Research Paper

\title{
A POPULAR SCIENCE VIDEO PROGRAM PROPOSED FOR PROMOTING SCIENTIFIC LITERACY IN WATER DISASTER SOLUTIONS ADAPTING CLIMATE CHANGE
}

\author{
Yi-Ching Chen ${ }^{1}$, Michelle Hui Lee ${ }^{2}$, Fu-Ming Chang ${ }^{3}$, Mei-Xiu Lai ${ }^{4}$ \\ ARTICLE HISTORY
}

Received: February 12, 2019 Accepted: May 22, 2019

Publish on: June 25, 2019

\section{ABSTRACT}

Under climate changes, the traditional water control thinking has long been obsolete. "Adaptation" has been considered as one of the strategies for climate change. In addition to the adjustment of engineering technology and water management strategies, there are still non-engineering aspects considerations, too. Climate change has never been a simple question to wait for a simple answer. The sustainable development of water management strategy requires not only good scientific research and good communication, but also trustworthy science, clear policies, creative business opportunities and public participation. Sometimes, after damage, quarrel provoked by the people's grievances and public opinion also caused disaster, too. The reason behind this is that people have lack sufficient knowledge in science, let alone scientific literacy and the recognition of scientific value under extreme climate. The expression of the story in this popular science video will allow people to experience the universal value of the life community in which people and water are closely interdependent.

Keywords: Climate change, adaptation, water control, non-engineering aspect, popular science video.

\section{Introduction}

Scientific knowledge is such a medium which leads people to look at the world from different angles. In addition to its practical value, it is more aesthetic. Popular science is an interpretation of science intended for a general public. It is presented in many forms, including books, magazine articles, video (film and television documentaries), and web pages (Wikipedia, 2019). It is hoped that the general public can have basic scientific literacy, can read and listen to science, and basically understand current affairs or news related to science. Science and technology must rely on popular science to spread the public. If scientific concepts can spread to the public, the quality of the people can be improved and social development can be promoted.

When scientists are able to communicate effectively beyond their peers to broader, non-scientist audiences, it builds support for science, promotes understanding of its wider relevance to society, and encourages more

$\checkmark$ Yi-Ching Chen

Corresponding author: yiching@mail.dyu.edu.tw

${ }^{1}$ Department of Environmental Engineering, Da-Yeh University, Changhua, Taiwan

${ }^{2}$ Creation Production, Co., Taipei, Taiwan

${ }^{3}$ Department of Environmental Engineering, Da-Yeh University, Changhua, Taiwan

${ }^{4}$ Department of Environmental Engineering, Da-Yeh University, Changhua, Taiwan 
informed decision-making at all levels, from government to communities to individuals. It can also make science accessible to audiences that traditionally have been excluded from the process of science. It can help make science more diverse and inclusive (Feliú-Mójer, 2015). Contemporary scientific communication is the "science education of the public", which is aimed at the whole society and enables those people finishing normal school education still be able to contact scientific knowledge and scientific methods, and people can use rational thinking to understand the living environment of human beings and apply science to life.

The water disaster problems under climate change are seriously concerned now. The natural reversal of climate change is likely to trigger a human catastrophe at any time. The "water" closest to human life and property is the most important. At present, the flood and drought situation in various countries has become more and more serious, and even more the water pollution and reclaimed water have become the priority issue of all countries. In fact, the World Economic Forum (2018) published a global risk assessment report that has pointed out that climate change, extreme rainfall and water resources crisis have ranked among the top five risks in the world and deserve the attention to all people. Adaptation and mitigation are two major national action strategies today for all countries. It is also necessary to formulate short-term to long-term action strategies to cope with water disaster caused by climate change.

However, people always thinks that the government can solve the problems in drought and flood by investing abundant money in engineering works. This is a serious fallacy: we cannot look at the drought and flood problems as traditional technical projects only, such as construction of dikes and dams. The reason behind it is that people lack sufficient scientific knowledge in dealing with water disaster, let alone the scientific literacy in the treatment of water problems.
2. Scientific literacy, Scientific communication, and Popular science video

\subsection{Scientific literacy}

When the word "science" is no longer a "stuff for exams", it needs to start from everyday life, then science literacy becomes one of the most important. Only when individuals have the ability to acquire, process, and understand basic scientific information can they choose the right response, and even have curiosity and interest in knowledge, from which they can reflect, think dialectically, and participate. Orzel (2014) in his excellent book "Eureka: Discovering Your Inner Scientist" said, "science is what makes us human". As a human, a scientific literate person is expected to be able to do the following (Allian, 2015):

- Build a model based on experimental evidence (physical model, conceptual model, mathematical model).

- Use and understand some existing models (you can't build everything yourself).

- Understand the limitations of science.

- Think of an experiment to test a particular model.

Scientific literacy has received attention over the years, but there is virtually no consensus on its definition and a number of different factors that influence interpretations of this concept (Laugksch, 2000). Ogunkola (2013) collected explanations offered for importance of scientific literacy to conclude that it helps citizens to comprehend the potentials and abuses of science. It also helps citizens to make informed decisions about basic everyday problems and vote on the numerous issues that require some scientific acknowledge.

\subsection{Scientific communication}

In 2011 a "Popular Science Communication Industry Development Plan" was promoted in Taiwan and scientific communication, here, is defined as a communication activity that transmits technology and scientific knowledge, methods, thinking and spirit, and cultivates the 
scientific literacy of the whole people. With the embarrassment of the economic era, in addition to school education, the communication media has become the most important channel of scientific knowledge for the people. Nowadays, communications technology is advancing by leaps and bounds, the impact of media information on the social environment is ubiquitous. Undoubtedly, when the media has become the most important source of people to establish a worldview and values, media literacy education is also particularly important.

Science communication is defined as the use of appropriate skills, media, activities, and dialogue to produce one or more of the following personal responses to science (the AEIOU vowel analogy, Burns et al., 2003):

- Awareness: access to scientific information;

- Enjoyment: appreciate the various processes and performances of science;

- Interest: inspired by the spontaneous participation of science;

- Opinion-forming: encourage to take the initiative to generate opinions;

- Understanding: to understand scientific content, scientific processes, and social factors.

\subsection{Popular science video}

The communication media can be books, magazines, newspapers, and furthermore, digital video and animations. Google has predicted that after $2020,90 \%$ of the network stream flow will come from the video, and $92 \%$ of people will look through the Internet for their own information or answers, then after videos become the best solution choice. Some great popular science videos are common on BBC, National Geographic, Discovery Channel, but why are these videos so attractive? The characteristics of these videos may be (1) there is a solid team, including science, scriptwriting, animation, photography and other production staff, (2) sufficient funds, (3) presenting capabilities with good writing, speaking, images, (4) proper background music, (5) video with clear target, main scope, structure, and intention of the whole piece.

To communicate scientific information adequately, the mass media need to provide suitable information and channels so the community can acquire new information, and thus innovations can be generated. In addition, new media have become quite important and convenient for a new generation. Using videos or graphic images would be easier for an audience to understand scientific concepts (Tsai, 2017).

\section{Video Production Planning for " 2025 Asking Water"}

\subsection{Background for water disaster solu- tions}

The ancient Chinese poet $\mathrm{Qu}$ Yuan's "Ask Heaven" of "Li Sao": "Why is winter warmer, why is summer colder?" which pointed out the anomaly of the weather and predicted the phenomena that human beings are currently facing. The year of 2025 is a key number in IPCC to remind us that there should be specific actions to mitigate and adapt the climate change. Therefore, a topic of popular science video program with "2025 Asking Water" Figure 1 is proposed to match the subject to find the solutions for water disaster.

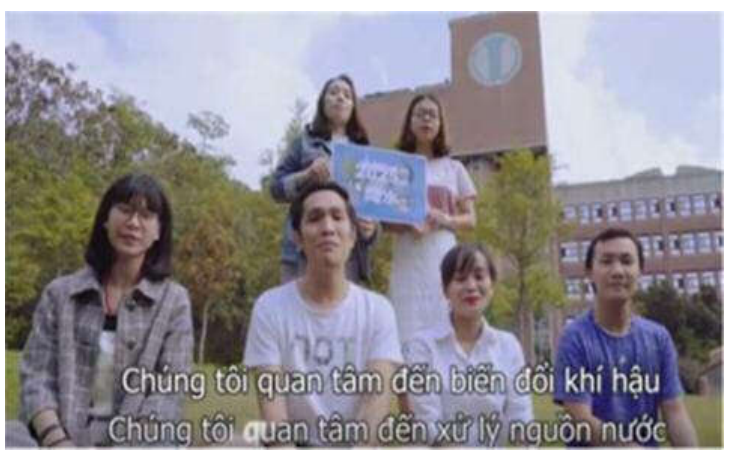

Fig. 1. Part scene of "2025 Asking Water"

Under the constant extreme changes in the climate, the traditional water control thinking has long been obsolete. Climate change is not a simple question to be coped with a simple answer. A sustainable development strategy for climate change and water management requires not only 
good scientific research and good communica- economic analysis based on science concepts. tion, but also trustworthy science, clear policies, Many scientists also predict that the "water recreative opportunities and public participation. sources" competition will be the biggest interEven William D. Nordhaus and Paul M. Romer, national crisis after the end of the Cold War. the 2018 Nobel Prize winners in Economic Sci- Many water topics are concerned and 13 ences, try to integrate climate change and tech- episodes are planned in this popular science nological innovation into long-term overall video program as list of Table 1.

Table 1. Planned episodes in popular science video program

\begin{tabular}{ll}
\hline & The impact of climate change on water disasters is global, \\
& not just Taiwan. There were many heavy rain events \\
occurred in the world just only in 2018: Japan, India, & Laos, Vietnam, South Korea, etc. Such heavy rains never \\
under climate change & occurred. It will remind us that every country must be \\
prepared and take action on water disasters under climate & change! \\
(2) Wisdom of coexistence & $\begin{array}{l}\text { In recent years, the extreme rains, super hurricanes or } \\
\text { typhoon have continuously tested the ability of each } \\
\text { with water } \\
\text { understand our own terrain and culture, and face different } \\
\text { problems and resources before we can propose a suitable } \\
\text { solution. } \\
\text { In recent years, global climate anomalies and the } \\
\text { frequency of droughts and floods have increased year by } \\
\text { year. Due to the large changes in the topography of } \\
\text { Taiwan and the steep terrain of the catchment area, } \\
\text { conserving water is truly difficult. Also the uneven } \\
\text { distribution of rainfall and dryness make much efforts to } \\
\text { prevent and control floods and droughts. Taiwan faces } \\
\text { the difficulty in developing and deploying of water } \\
\text { resources, and it needs to take into account the diversified } \\
\text { challenges of natural and hydrophilic environment. }\end{array}$ \\
\hline
\end{tabular}


In response to climate change, which brings extreme rainfall and possible water supply risks, the Taiwan government has a forward-looking strategy and complete

(4) Water depletion in Taiwan planning for solving water resources problems, and actively promotes various facilities and management efforts to ensure that all water is without depletion. Opening new water sources, saving water, dispatch and backup are the four major measures of effective strategies for solving water problems.

In recent years, population has increased and urban expansion, industrial development, coupled with

(5) Discolored rive-water pollution

(6) Urbanization water environment

(7) Floodplain in the city deforestation, poor conservation make that the mountains are no longer green and the rivers are dirty. Understanding water pollution, what we should do is to face and solve it under climate change.

As result of urbanization, costs of preventing flood are rising and people's tolerance for flooding is reduced. Restricted traffic and underground pipeline problems cause difficulties in improving existing rainwater sewer. Integrated water management can make city becoming a city of "water conserving, permeable, flood preventing and ecology".

Floodplain management is a decision-making process that aims to achieve the wise use of the city floodplains. "Wise use" means both reduced flood losses and protection of the natural resources and function of floodplains.

In 2018 a torrential rain in southern Taiwan caused city's flood problems. The rainfall was about $694 \mathrm{~mm}$ within 72 hours due to tropical depression and its peripheral circulation. A storm just like typhoon, The 24 hours of

(8) Storm like typhoon rainfall in this storm was more than it on the most terrible Typhoon Morakot ever happened in Taiwan. The concept of detention pond is to regulate floods, delay flood peaks, increase infiltration, and reduce flooding, etc. 
Following the increasing of domestic water consumption, and the further depletion and pollution of freshwater resources, the use of water has become the focus of

(9) Black water becomes gold attention around the world. Reclaimed water can take on the role of stabilizing water resources. Reclaimed water will also integrate the renewable water-related industrial chain with the business opportunity of "black water becoming gold"

Strata subsidence is one of the causes of flooding, and another challenge dealing with extreme climate change.

(10) Reborn of strata subsidence area There are engineering and non-engineering aspects in flood prevention at strata subsidence area. Besides the drainage improvement in engineering works, enhanced early warning evacuation and runoff sharing are proposed in non-engineering works at land development.

Under climate change, many cities are likely to face

(11) Separation line of flood and drought dangerous conditions lust standing on separation line of flood and drought. With the natural terrain of Taiwan, several cities have been tested in this way.

According to the United Nations, green agriculture incorporates ideas and guidelines from different conceptual areas. These are fair trade, ecological

(12) Green agriculture agriculture, organic or biodynamic agriculture, as well as conservation agriculture. Green Agriculture: will be foundations for biodiverse, resilient and productive agricultural systems.

Facing the water disaster under climate change, many countries think about the urban planning concept of "city

(13) City ark ark" to remind humans that this is a "catastrophe"! We must re-examine the fragile ecological balance between mankind and nature with a serious attitude. 


\subsection{The importance of scientific communi- cation in this video program}

- Strengthen the necessary knowledge through the truth that must be faced. Through this video program, the project intends to let the public know the cross-domain science of water control. It is easy to understand that popular science will make it no longer "unreachable" and easy to accept and absorb.

- Remind the people to be prepared for danger, to respect the heavens, and to recognize the meaning of science in civilization developing. The concept of new thinking and pluralistic water control through the design of video program, when the public understands that the adjustment measures for water control with scientific evidence, it will enhance people to concern about water control issues, and present enthusiasm to join the mission.

- Inspire a new dialogue between people and "water". Crisis is a turning point. The seriousness of the "water" crisis and the urgency of response have led to the research and development of new technologies, engineering and non-engineering thinking, and stimulated the new generation to further explore in science.

- Allow the concept of popular science to take root through far-reaching digital convergence. The dissemination of video production through the digital convergence can improve the understanding the popular science knowledge as well as being an important reference for exploring relevant issues.

\section{Conclusion}

Therefore, an in-depth popular science video program with complete information is proposed to: (1) strengthen the necessary knowledge through the truth that must be faced; (2) remind the people to be prepared for danger, to respect the heavens, and to recognize the meaning of science in civilization developing; (3) inspire a new dialogue between people and "water"; (4) allow the concept of popular science to take root through far-reaching digital convergence.

This project is not only a popular science video program, but also has the following features and other added value. Trough attractive streaming media to create a rich audio-visual feast this video program can be a most vivid teaching material for popular science textbooks in climate change to feel the natural wonders of the knowledge of earth science. The expression of the story in video allows people to experience the universal value of the life community in which people and everything, such as water are closely interdependent. Also, the narrative style of situational aesthetics makes people have true feel about water disaster and solutions under climate change.

\section{References}

1. Allian, R., 2015. What Does Scientific Literacy Really Mean? Wired: science. Avaliable online: https:/www.wired.com/2015/08/scientific-literacy-really-mean/ (accessed on 24 February 2019).

2. Burns, T.W., O’Connor, D.J., Stocklmayer, S.M., 2003. Science communication: a contemporary definition. Public Understanding of Science, 12 (2): 183-202.

3. Feliú-Mójer, M.I., 2015. Effective Communication, Better Science. Guest Blog in Scientific American. Avaliable online: https://blogs.scientificamerican.com/guestblog/effective-communication-better-science/ (accessed on 24 Feb 2019).

4. Laugksch, R.C., 2000. Scientific literacy: A conceptual overview. Science Education, 84 (1): 71-94.

5. Ogunkola, B.J., 2013. Scientific Literacy: Conceptual Overview, Importance and Strategies for Improvement. Journal of Educational and Social Research, 3 (1): 265-274.

6. Orzel, C., 2014. Eureka: Discovering Your Inner Scientist. NY: Basic Books.

7. Tsai, M., 2017. Producing and Communicating an Interactive Popular Science Video for 
New Media: Using as an Example the Theme of lar_science (accessed on 21 February 2019). Marine Microplastics Spelling Big Problems for 9. World Economic Forum (WEF), 2018.

Future Generations. Proceedings of The Global Risks Report 2018, 13th PICMET'17, Oregon, USA.

Edition. Avaliable online: https://www3.wefo-

8. Wikipedia, 2019. Popular science. Avali- rum.org/docs/WEF_GRR18_Report.pdf able online: https://en.wikipedia.org/wiki/Popu- （accessed on 24 February 2019). 